\title{
A Lot of Warmth and a Bit of Control? How Parenting Mediates the Relationship Between Parental Personality and Their Children's Mental Health Problems
}

\author{
Caroline Cohrdes $\mathbb{D}^{1} \cdot$ Kristin Göbel $^{1}$
}

Accepted: 6 December 2021 / Published online: 4 January 2022

(c) The Author(s) 2022

\begin{abstract}
Research has identified parental personality and parenting behaviour as important contributors to healthy child development. However, indirect associations are largely unknown. The current study aimed to investigate the mediating role of parenting dimension relations between parental personality and adolescent mental health problems. The cross-sectional sample included 4258 German adolescents (48.7\% male, 11-17 years) and one parent who participated in a national health survey (KiGGS Wave 2). The results underline and extend previous indications of direct associations between parental personality and their children's mental health problems by highlighting the adverse role of neuroticism. Furthermore, new insights are added regarding the mediating roles of parenting dimensions (i.e., warmth, behavioural control, and psychological control). Future efforts and parent-focused prevention programmes should be extended by parental personality to identify maladaptive parenting behaviour and thus contribute to the development of their children's mental health.
\end{abstract}

Keywords Externalizing problems $\cdot$ Internalizing problems $\cdot$ Adolescence $\cdot$ Parental personality $\cdot$ Parenting

\section{Highlights}

- Parental personality is indirectly related to adolescent mental health through parenting.

- Parental neuroticism and psychological control are associated with adolescent mental health problems.

- Parental conscientiousness and warmth are associated with adolescent mental health.

- Parental openness and agreeableness require more scientific attention.

- Further efforts are needed to provide preventive measures considering parental personality.

Childhood and adolescence are characterized by an increased vulnerability to mental health problems affecting approximately one-fourth of children and adolescents worldwide (Kieling et al., 2011, Klipker et al., 2018, Paus et al., 2008, Polanczyk et al., 2015). Mental health problems are commonly conceptualized as two broad dimensions of internalizing (directed mostly inwardly, e.g., depression and

These authors contributed equally: Caroline Cohrdes, Kristin Göbel

$\square$ Caroline Cohrdes

CohrdesC@rki.de

1 Mental Health Unit, Department of Epidemiology and Health Monitoring, Robert Koch Institute, General-Pape-Str. 62-66, 12101 Berlin, Germany anxiety) and externalizing problems (directed mostly outwardly, e.g., anger and aggression; Goodman et al., 2010). Already established problems remain relatively stable throughout childhood and adolescence and confer risk for a wide range of negative outcomes, including low achievement in school, delinquent behaviour, relationship difficulties, and poor well-being (Baumgarten et al., 2018, Patel et al., 2007, Picoito et al., 2021). Substantial research has shown that multiple factors elevate the risk for mental health problems in children and adolescents; more precisely, risk factors from the family domain, such as family dysfunction, parental psychopathology, parental personality and parenting style, are among the most important predictors of negative mental health outcomes (Bayer et al., 2019, Bayer et al., 2011, Evans et al., 2013, Göbel \& Cohrdes, 2021, Wang et al., 2019). However, prior research results underscore the need for early prevention that 
effectively targets mental health risk factors for children and adolescents that can be addressed through parental education (e.g., Wang et al., 2019).

\section{Parental Personality and Adolescent Mental Health Problems}

Over the last decade, research has identified parental personality as an important contributor that may directly influence children's mental health development (Bertino et al., 2012, Nigg \& Hinshaw, 1998, Ortiz Ruiz, 2018, Puff $\&$ Renk, 2016). For instance, Bertino et al. (2012) found a positive association between parental borderline and antisocial personality patterns and their children's externalizing behaviour problems, with stronger relationships for adolescents than for children. Most studies investigating parental personality and children's mental health have focused on parental neuroticism, which relates positively to psychosocial problems among their children (i.e., conduct disorders and hyperactivity) (Amrock \& Weitzman, 2014, Nigg \& Hinshaw, 1998, Prinzie et al., 2004, Sahithya \& Raman, 2021).

Fewer studies concentrate on other personality dimensions of the well-known five-factor model of personality, which sufficiently described individual differences using five main factors: neuroticism (absence of emotional stability, e.g., frequent feelings of irritability and anger), openness to new experiences (e.g., curiosity, imagination), conscientiousness (e.g., self-discipline and duty), extraversion (e.g., outgoing, interpersonal contact), and agreeableness (e.g., altruism and empathy) (John et al., 2008). Whereas high neuroticism has been related to negative health practices and outcomes, opposite findings have been reported for high conscientiousness. Parents who rated themselves as more conscientious supported their children's behavioural adjustment (Oliver et al., 2009) and provided a beneficial parent-child interaction (Hong et al., 2015). Extraverted parents were more likely to have warm interactions with their children by displaying affection and love (Bornstein et al., 2011, Sahithya \& Raman, 2021). One review by Belsky and Barends (2002) concludes that low parental neuroticism, high parental extraversion, and high parental conscientiousness are most likely beneficial for children's psychosocial development. More recent research has confirmed mothers' high extraversion and high conscientiousness, as significant predictors of children's mental health with lower internalizing problems (Ortiz Ruiz, 2018, Puff \& Renk, 2016). However, inconclusive results have been documented for the association between parental agreeableness and openness to new experience and children's mental health (Nigg \& Hinshaw, 1998, Oliver et al., 2009, Ortiz Ruiz, 2018, Prinzie et al., 2004).
Possible explanations for the relations between parental personality and children's mental health have been derived from stress reactivity (Bolger \& Schilling, 1991) and attachment theory (Fraley \& Shaver, 2008). Stress reactivity theory highlights the effect of personality on the way people approach and react to stressful situations and its influence on (mental) well-being (Bolger \& Schilling, 1991, McCrae \& Costa Jr, 2003, Wrosch \& Scheier, 2003). Recent findings report evidence that parents with high neuroticism show higher psychological distress and react more negatively to their children's needs and problems (Mazza et al., 2020, Ortiz Ruiz, 2018). Parental feelings of anger, insecurity, and perceived powerlessness combined with poor emotion regulation (i.e., neuroticism) influences the relationship with their child, which in turn may predict behavioural problems (Mazza et al., 2020).

In contrast, attachment theory proposes that securely attached individuals are more likely to feel protected and belonging, and interact with others in a confident and open manner, as they seem to develop "promoting" characteristics such as positive affectivity, healthy autonomy, and resilience (Fraley \& Shaver, 2008). Research supports this assumption by providing evidence for a positive association between insecure attachment and neuroticism or negative correlations with agreeableness and extraversion (Noftle \& Shaver, 2006). Additionally, parents with paranoid personality traits may not be able to provide a secure environment and may expose children to significant psychological stress, hindering a positive attachment relationship (Bertino et al., 2012). According to Deb and McGirr (2015), parents' personality dispositions and nurturing care are essential for healthy mental child development.

\section{Parenting and Adolescent Mental Health Problems}

Evidence suggests that positive parent-child interactions lay a foundation for the development of child and adolescent mental health (Achtergarde et al., 2015, Göbel \& Cohrdes, 2021). As primary contacts, parents provide adequate resources, care, affection, and control to foster child and adolescent healthy development and adjustment (Anaya \& Perez-Edgar, 2019, Buschgens et al., 2010, Steinberg \& Silk, 2002). Within their role, parents are faced with the challenge of adjusting levels of control to fit their children's needs for self-definition and autonomy (Buschgens et al., 2010, Mastrotheodoros et al., 2018, Steinberg \& Silk, 2002). Although the needs for autonomy and social relations outside the home increase in middle adolescence, the role of parents remains important at this stage, as indicated by evidence that positive parent-child relationships are 
associated with fewer adolescent mental health problems (Hair et al., 2008, Moilanen et al., 2015).

The effect of parenting behaviours on child and adolescent mental health outcomes has been a focus of investigations for the last 20 years (Aunola \& Nurmi, 2005, Bayer et al., 2019, Calders et al., 2020, Huver et al., 2010, Milevsky et al., 2006, Petito \& Cummins, 2012, Pettit et al., 2001, Raboteg-Saric \& Sakic, 2013). Parenting can be either characterized as situational behaviours or combinations of specific parenting behaviours (i.e., parenting styles; Baumrind, 1971) or as general parenting strategies (i.e., parenting dimensions; Calders et al., 2020). With a focus on parenting dimensions, previous research has identified an affective dimension comprising warmth and support (e.g., responsiveness, acceptance) and a disciplinary dimension that entails parental control (Prinzie et al., 2009, Scaramella et al., 1999). Parental control can be subdivided into behavioural control (e.g., monitoring, setting limits) and psychological control (e.g., love withdrawal, guilt induction; e.g., Aunola \& Nurmi, 2005, Barber et al., 1994, Pettit et al., 2001). High levels of parental warmth were associated with a positive development of adolescent mental health (Calders et al., 2020, Yap \& Jorm, 2015). Evidence on the effects of behavioural control is more mixed regarding its association with children's mental health problems, which may be due to different approaches towards its operationalization (Calders et al., 2020). Nevertheless, the majority of findings suggest beneficial effects of parental behavioural control and warmth for children's mental health, self-esteem, quality of life, and life satisfaction (Garcia et al., 2020, Pettit et al., 2001, RabotegSaric \& Sakic, 2013, Steinberg, 2001). As opposed to parental warmth and behavioural control, levels of parental psychological control are associated with externalizing (Mabbe et al., 2019, Pettit et al., 2001, Pinquart, 2017) as well as internalizing problems (Barber et al., 1994, Mabbe et al., 2019, Scaramella et al., 1999). A major knowledge gap constitutes the lack of studies investigating parental personality dimensions (i.e., Big Five), their interplay with children's mental health problems, and the role of parenting.

\section{The Mediating Role of Parenting}

According to the Belsky (1984) classic process model, parental characteristics (e.g., parents' personality) determine among other factors parenting behaviour which in turn influences children's mental health development (Hutchings \& Lane, 2005). Parental personality has been identified "as an inner resource that affects parenting" (Prinzie et al., 2009 , p. 351) and the most important predictor to influence parenting styles (Sahithya \& Raman, 2021, Vafaeenejad et al., 2018).
Relatively few studies have examined the mediating role of parenting between parental personality and their children's mental health (Brook et al., 2002, Oliver et al., 2009, Prinzie et al., 2004, Puff \& Renk, 2016). For instance, studies indicate that parental neuroticism is linked to disrupted discipline, which in turn predicts problem behaviours in adolescence (Brook et al., 2002, Prinzie et al., 2004). In contrast, parents who are high on extraversion show more responsive and encouraging parenting behaviour (Puff \& Renk, 2016). According to the longitudinal study by Oliver et al. (2009), parents high in conscientiousness are more likely to set limits (i.e., behavioural control); this, in turn, was related to fewer externalizing problems in adolescence. Agreeableness, openness to experience, and conscientiousness were associated with a parenting style related to high warmth and control (Vafaeenejad et al., 2020). However, those studies mainly focused on parental behavioural control rather than psychological control. Although literature emphasizes the importance of parental personality and its influence on children's development, too little attention in empirical research was directed towards parenting quality (Bahrami et al., 2018, Puff \& Renk, 2016, Sahithya \& Raman, 2021). Foremost, we need to understand the factors influencing parenting in order to develop prevention and intervention programmes targeting child mental health outcomes (Gölcük \& Berument, 2019). The current study extends the limited literature by examining the links between parental personality traits and parenting dimensions and adolescents' mental health. Based on the aforementioned research, we hypothesized that high parental neuroticism is related to a higher risk of adolescent mental health problems. Furthermore, we expected high parental conscientiousness and extraversion to be related to fewer adolescent mental health problems differentiated between internalizing and externalizing problems. In addition, the current study explored relations between parental openness and agreeableness and adolescent mental health problems.

Second, we hypothesized that parenting characterized by warmth and support as well as by behavioural control are associated with fewer adolescent mental health problems, whereas high psychological control is associated with a higher risk of adolescent externalizing and internalizing problems.

Finally, we hypothesized that parental personality is indirectly linked to adolescent mental health through parenting dimensions. More precisely, we expected parenting characterized by behavioural control to partially mediate the relationship of parental conscientiousness and neuroticism with their children's mental health problems. To address current research gaps, we also explored the mediating roles of two other parenting dimensions (i.e., warmth, psychological control) on the association between parents' personality and their children's mental health problems. 


\section{Methods}

\section{Sample and Procedure}

These study data are part of the German Health Interview and Examination Survey for Children and Adolescents (KiGGS), a health-monitoring system established at the Robert Koch Institute. The KiGGS cross-sectional survey was conducted between 2014 and 2017 at 167 sample points across Germany (KiGGS Wave 2). KiGGS Wave 2 used a nationally representative probability sample of 15,023 children and adolescents (49.8\% male) aged 0-17 years. A detailed description of the survey methodology can be found in Mauz et al. (2017) and Lange et al. (2018). In brief, one parent (82.5\% mothers) of the recruited children and adolescents provided information on a wide spectrum of health-relevant topics. KiGGS Wave 2 was conducted in accordance with the data protection provisions set out in the Federal Data Protection Act, and the Hannover Medical School's Ethics Committee approved the study (No 22752014). The present analyses are based on a subsample of 4258 adolescents ( $48.7 \%$ male) ranging in age from 11 to 17 years $(M=14.0$ years, $S D=2.0)$ and one parent. Written informed consent was obtained from the parents.

\section{Measures}

\section{Adolescent mental health problems}

A parent completed the validated German version of the 25item Strength and Difficulties Questionnaire (Goodman, 1997, Klasen et al., 2000) for their adolescent child. Items are rated from 0 (not true) to 2 (certainly true), and responses indicate mental health problems in various contexts. Scores on the subscales "emotional problems" (e.g., often unhappy) and "peer problems" (e.g., bullied by others) were combined to indicate internalizing problems (SDQint), and scores on the subscales "conduct problems" (e.g., lies or cheats frequently) and "hyperactivity" (e.g., restless, overactive) were combined to indicate externalizing problems (SDQext), as suggested by previous theoretical and empirical evidence (see Goodman et al., 2010). Cutoff scores of $>7$ (SDQint) and $>9$ (SDQext) were used to generate two categorical variables, indicating $0=$ no mental health problems and $1=$ mental health problems, as indicated by German norm values (Woerner et al., 2004). Cronbach's alpha, as an indicator for the internal consistency of scales, was 0.78 for SDQext and 0.73 for SDQint.

\section{Parental personality}

Personality traits were measured using items on the "Big Five" dimensions of openness to new experience $(\mathrm{O})$, conscientiousness (C), extraversion (E), agreeableness (A), and neuroticism (N) (German version of the BFI-10; Rammstedt \& John 2007); each scale is represented by two items. Responses were rated on a 5-point scale from 1 (not at all) to 5 (totally) and summarized to a total score for each subscale. Rammstedt and John (2007) showed good validity of the 10-item BFI personality inventory, as suggested by replication of the factorial structure and average correlations of 0.69 with the NEO-PI-R personality scales. Interitem correlations in the present study were $r=0.31(p<0.001)$ for openness, $r=0.29(p<0.001)$ for conscientiousness, $r=0.51(p<0.001)$ for extraversion, $r=0.27(p<0.001)$ for agreeableness, and $r=0.26(p<0.001)$ for neuroticism.

\section{Parenting dimensions}

One parent completed a 27-item inventory to measure parenting dimensions (ZKE; Reitzle et al., 2001) rated from 0 (not at all) to 3 (completely true). The inventory is composed of three subscales: "warmth and support" (hereafter referred to as warmth; 12 items; e.g., "I respect my child's opinion even if I have another opinion"), "rules and behavioural control" (hereafter referred to as behavioural control; six items; e.g., "I always want to be asked before my child goes out"), and "psychological control" (nine items; e.g., "I often want to change something about my child"). A mean score for each subscale was created for the analysis. Cronbach's alpha for warmth was 0.88 , for behavioural control 0.72, and for psychological control 0.74 .

\section{Parental socioeconomic status (SES)}

The SES represents an index score developed by Lampert et al. (2014). The index is built on the basis of three components that were assessed from the parents: the education qualification index (International Comparative Analysis of Social Mobility in Industrial Nations cassification CASMIN; Brauns et al., 2003), the occupational status index (International Socio-Economic-Index of Occupational Status ISEI; Ganzeboom \& Treiman, 2003), and net equalized income (according to the federal government's poverty and wealth reporting guidelines and the recommendations for reporting on social cohesion in Europe). In the present analyses, SES was used as a distribution-based variable containing three categories that reflect the ranking of children by the social status of the households in which they live: low (lower quintile), medium (second to fourth quintile), and high (upper quintile; see in more detail in Lampert et al., 2014). In the present sample, $11.6 \%$ of children and adolescents had a low SES (95\% CI, 10.7 to 12.6 ), $66.3 \%$ (95\% CI, 64.9 to 67.7$)$ a moderate SES, and $22.1 \%(95 \%$ CI, 20.9 to 23.3) a high SES. 


\section{Parental well-being}

One parent answered the 8-item adult Personal Well-Being Index (PWI-A; Cummins et al., 2003), which comprises questions on satisfaction with the following quality of life domains: standard of living, health, life achievement, personal relationships, personal safety, community connectedness, future security, and spirituality/religion. Responses were rated using a scale from 0 to 10 and were summarized to a total score. Cronbach's alpha was 0.88 .

\section{Statistical Analyses}

Analyses were conducted in two steps. First, means or proportions, confidence intervals, and bivariate correlation analyses were obtained for all variables: sociodemographic characteristics, mental health problems (SDQint, SDQext), parental personality (OCEAN), and parenting dimensions (warmth, behavioural control, and psychological control). Second, we calculated a path model testing the associations between parental personality and parenting dimensions and adolescent mental health problems. Additionally, we examined the mediating roles of parenting dimensions on the associations between parents' personalities and their children's mental health problems. Adolescents' age, sex, parental SES, and well-being were treated as control variables.

We performed structural equation modelling (SEM) to fit the proposed structural model to the data using the software package Mplus 7 (Muthén \& Muthén, 2011). The two categorical outcomes (SDQint, SDQext) were estimated using weighted least squares estimation with a mean- and variance-adjusted (WLSMV) estimator. The indirect effects were modelled with the MODEL INDIRECT option. The significance of the indirect effects was determined using bias-corrected bootstrap 90\% Cis (MacKinnon et al., 2004). Confidence intervals that did not include zero indicated mediating effects. To further analyse the indirect effects, we calculated the standardized indirect effect for each association (Preacher \& Kelley, 2011) and the proportion of the total effect explained by the indirect effect (PEID). The PEID is indicated by the product of standardized beta coefficients of the direct paths from parental personality on parenting and parenting on adolescent mental health problems divided by the total effect from parental personality on adolescent mental health problems.

Due to its sensitivity to sample size, the significance of the chi-square test does not provide useful information on model fit, and other measures need to be considered (Kenny, 2020, Kline, 2015). As recommended by $\mathrm{Hu}$ and Bentler (1999), several well-established indices with values indicating a good model fit were estimated; a comparative fit index $(C F I)$ and Tucker-Lewis index $(T L I)$ above 0.90, and a root mean square error of approximation (RMSEA) less than or equal to 0.06 , indicate acceptable fit. Mplus incorporates all cases, including those missing at random, using the full information maximum likelihood (FIML) approach. Missing data for the predictor variables were at maximum $5.2 \%$ (extraversion).

\section{Results}

Table 1 shows the means or proportions, confidence intervals, and bivariate correlation analyses obtained for mental health problems (SDQint, SDQext), parental personality (OCEAN), parenting dimensions (warmth, behavioural control, and psychological control), and control variables.

The results from SEM analyses indicated excellent fit of the proposed model to the present data, $\chi^{2}=3151.75(p<$ $0.001), C F I=1.00, T L I=1.00, R M S E A<0.01, R^{2}=0.39$. We calculated a second model that also included age and sex interactions with parenting dimensions on adolescent mental health. However, the inclusion of interaction terms did not contribute to a better fit of the model. In contrast, the interaction model displayed poor fit, $\chi^{2}=40913.96(p<0.001)$, $C F I=0.27, T L I=-1.38, R M S E A=0.74, R^{2}=0.28$.

As shown in Fig. 1, adolescent internalizing problems were directly associated with high parental neuroticism and low conscientiousness as well as extraversion. Unexpectedly, adolescent externalizing problems were directly associated only with low parental conscientiousness. No direct link was found for agreeableness or openness to new experience.

Parenting characterized by warmth was related to fewer adolescent externalizing problems, while parental behavioural control was related to fewer internalizing problems but not vice versa. However, parents who exhibited more psychological control showed a higher risk of adolescent externalizing and internalizing problems. Overall, relations between parent personality and parenting dimensions with adolescent mental health problems were relatively small (e.g., conscientiousness and SDQint, $\beta=0.06$ ) to moderate (e.g., psychological control and SDQext, $\beta=0.31$ ).

All five personality dimensions were linked to parental warmth, whereby four characteristics except openness to new experience were associated with behavioural control. Psychological control was related to neuroticism, openness to new experience, agreeableness and conscientiousness.

Furthermore, each of the five parental personality traits showed indirect relations with adolescent mental health, mediated by each of the three parenting dimensions. Whereas parental personality was directly and indirectly linked (i.e., partial mediation) to adolescent internalizing problems there were only indirect associations between parental personality and adolescent externalizing problems 


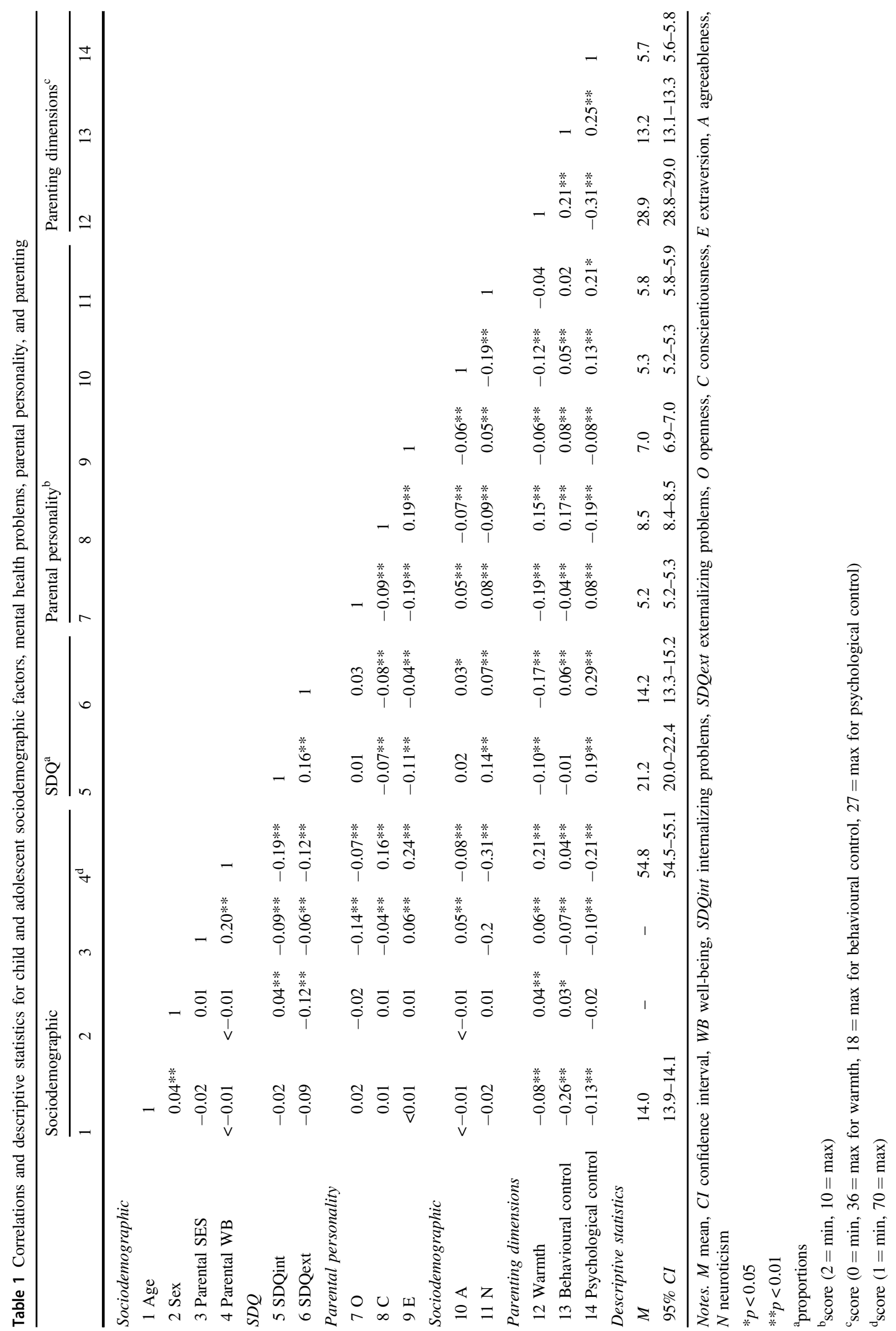


Fig. 1 Standardized coefficients from SEM showing total effects of parental personality (OCEAN) and parenting dimensions (warmth, behavioural control, and psychological control) on adolescent internalizing (SDQint; long-dashed lines) and externalizing problems (SDQext; short-dashed lines). Only significant paths are shown and marked by $* * p<0.01$ and $* p<0.05$. Age, sex, parental SES, and parental well-being are not shown in the figure but were included as covariates in the analyses. Model fit indices: $\chi^{2}=$ $3151.75, p<0.001, C F I=1.00$, $T L I=1.00$, RMSEA $<0.01$, $R^{2}=0.39$



indicating full mediation by parenting, except for conscientiousness (Table 2). Figure 2 displays the proportions of total effects explained by the indirect effects (PEID). As a result of additional analyses of each indirect association, when mediated by parental behavioural control, conscientiousness $(\beta=-0.01, S E=0.003, p<0.001)$, extraversion $(\beta=-0.03, \quad S E=0.001, \quad p=0.009), \quad$ and neuroticism $(\beta=-0.02, S E=0.001, p=0.018)$ showed negative associations with adolescent internalizing problems, whereas agreeableness showed a positive association $(\beta=0.03, \quad S E=0.001, \quad p=0.004)$. Openness to new experience was not associated with adolescent mental health problems via behavioural control. The proportions of the total effect explained by the indirect effect (PEID) were $9.6 \%, 4.0 \%, 3.0 \%$, and $4.2 \%$, respectively.

In contrast, parental warmth partly mediated the association between parents' personality and their children's externalizing problems but not their internalizing problems. While high levels of parental conscientiousness $(\beta=-0.03$, $S E=0.003, p<0.001$, PEID $=32.0 \%)$, and extraversion $(\beta=-0.01, S E=0.002, p=0.008, \quad$ PEID $=6.4 \%)$ were indirectly related to a lower risk of adolescent externalizing problems via parental warmth, the opposite pattern was found for high levels of openness $(\beta=0.03, S E=0.001$, $p=0.004$, PEID $=7.5 \%)$, agreeableness $(\beta=0.01, S E=$ $0.003, p<0.001$, PEID $=14.4 \%)$, and neuroticism $(\beta=$ $0.01, S E=0.002, p=0.029$, PEID $=4.8 \%$ ).

Parental psychological control mediated the association between parents' personality (except extraversion) and their children's internalizing and externalizing problems (Fig. 2). While high parental conscientiousness was related to fewer adolescent internalizing $(\beta=-0.03, S E=0.004, p<0.001$, $\mathrm{PEID}=34.5 \%)$ and externalizing problems $(\beta=-0.05$,
$S E=0.004, p<0.001$, PEID $=71.3 \%$ ) via parental psychological control, the opposite pattern was found for high levels of openness $(\beta=0.01, S E=0.004, \quad p=0.006$, $\mathrm{PEID}=4.1 \%$ for externalizing and $\beta=0.01, S E=0.003$, $p=0.007, \quad$ PEID $=18.4 \%$ for internalizing problems), agreeableness $(\beta=0.03, S E=0.005, p<0.001, \mathrm{PEID}=$ $71.3 \%$ for externalizing and $\beta=0.02, S E=0.004, p<$ 0.001 , PEID $=23.0 \%$ for internalizing problems), and neuroticism $(\beta=0.04, S E=0.005, \quad p<0.001, \quad \mathrm{PEID}=$ $46.5 \%$ for externalizing and $\beta=0.03, S E=0.004, p<$ 0.004 , PEID $=4.3 \%$ for internalizing problems).

\section{Discussion}

This study's objective was to provide a comprehensive overview of associations between various dimensions of parental personality and the mental health problems of adolescents. Additionally, new insights were anticipated for the explanatory role of parenting dimensions. The main aim was to derive recommendations for preventive public health measures.

\section{Parental Personality and Adolescent Mental Health Problems}

In accord with previous findings and our predictions, high parental neuroticism was associated with a higher risk of adolescent mental health problems (Nigg \& Hinshaw, 1998, Oliver et al., 2009, Prinzie et al., 2004, Sahithya \& Raman, 2021), although solely applying to internalizing problems. Following theoretical assumptions, associations between high neuroticism and mental health problems can be 
Table 2 Direct, indirect and total effects (standardized beta coefficients, standard error) from parental personality and parenting dimensions on child and adolescent mental health problems resulting from SEM

\begin{tabular}{|c|c|c|c|}
\hline & $\begin{array}{l}\text { Direct effect } \\
\beta \text { (SE) }\end{array}$ & $\begin{array}{l}\text { Indirect effect } \\
\beta(\mathrm{SE})\end{array}$ & $\begin{array}{l}\text { Total effect } \\
\beta \text { (SE) }\end{array}$ \\
\hline \multicolumn{4}{|c|}{ Internalizing problems $\left(R^{2}=0.14\right)$} \\
\hline Openness & $-0.05 *(0.024)$ & $0.01 *(0.005)$ & $-0.04(0.023)$ \\
\hline Conscientiousness & $-0.01(0.023)$ & $-0.04 * *(0.007)$ & $-0.06^{* *}(0.022)$ \\
\hline Extraversion & $-0.09 * *(0.023)$ & $<0.01(0.004)$ & $-0.09 * *(0.024)$ \\
\hline Agreeableness & $-0.01(0.022)$ & $0.02 * *(0.005)$ & $0.01(0.022)$ \\
\hline Neuroticism & $0.08 * *(0.024)$ & $0.03 * *(0.005)$ & $0.11 * *(0.023)$ \\
\hline Warmth & - & - & $-0.01(0.024)$ \\
\hline Behavioural control & - & - & $-0.06^{* *}(0.025)$ \\
\hline Psychological control & - & - & $0.23 * *(0.023)$ \\
\hline Age & - & - & $-0.02(0.022)$ \\
\hline Sex & - & - & $0.07 * *(0.021)$ \\
\hline Parental SES & - & - & $-0.07 * *(0.022)$ \\
\hline Parental well-being & - & - & $-0.15^{* *}(0.021)$ \\
\hline \multicolumn{4}{|c|}{ Externalizing problems $\left(R^{2}=0.24\right)$} \\
\hline Openness & $-0.03(0.025)$ & $0.04 * *(0.007)$ & $0.01(0.026)$ \\
\hline Conscientiousness & $-0.01(0.024)$ & $-0.08 * *(0.009)$ & $-0.09 * *(0.024)$ \\
\hline Extraversion & $0.01(0.026)$ & $0.01(0.006)$ & $0.03(0.027)$ \\
\hline Agreeableness & $-0.01(0.026)$ & $0.05 * *(0.006)$ & $0.03(0.027)$ \\
\hline Neuroticism & $0.01(0.026)$ & $0.05 * *(0.007)$ & $0.06(0.026)$ \\
\hline Warmth & - & - & $-0.16^{* *}(0.025)$ \\
\hline Behavioural control & - & - & $-0.01(0.026)$ \\
\hline Psychological control & - & - & $0.31 * *(0.024)$ \\
\hline Age & - & - & $-0.12 * *(0.022)$ \\
\hline Sex & - & - & $-0.18^{* *}(0.022)$ \\
\hline Parental SES & - & - & $-0.04(0.024)$ \\
\hline Parental well-being & - & - & $-0.11^{* *}(0.022)$ \\
\hline \multicolumn{4}{|l|}{ Warmth $\left(R^{2}=0.13\right)$} \\
\hline Openness & - & - & $-0.14 * *(0.015)$ \\
\hline Conscientiousness & - & - & $0.20 * *(0.016)$ \\
\hline Extraversion & - & - & $0.04 *(0.016)$ \\
\hline Agreeableness & - & - & $-0.09 * *(0.015)$ \\
\hline Neuroticism & - & - & $-0.03 *(0.016)$ \\
\hline Age & - & - & $-0.08 * *(0.014)$ \\
\hline Sex & - & - & $0.04 * *(0.014)$ \\
\hline Parental SES & - & - & $0.04 *(0.015)$ \\
\hline Parental well-being & - & - & $0.13 * *(0.019)$ \\
\hline \multicolumn{4}{|c|}{ Behavioural control $\left(R^{2}=0.11\right)$} \\
\hline Openness & - & - & $-0.03(0.016)$ \\
\hline Conscientiousness & - & - & $0.16^{* *}(0.016)$ \\
\hline Extraversion & - & - & $0.06 * *(0.015)$ \\
\hline Agreeableness & - & - & $0.07 * *(0.015)$ \\
\hline Neuroticism & - & - & $0.04 * *(0.016)$ \\
\hline Age & - & - & $-0.26^{* *}(0.015)$ \\
\hline Sex & - & - & $0.03(0.014)$ \\
\hline Parental SES & - & - & $-0.09 * *(0.015)$ \\
\hline Parental well-being & - & - & $0.04 *(0.017)$ \\
\hline
\end{tabular}


Table 2 (continued)

$\begin{array}{lll}\text { Direct effect } & \text { Indirect effect } & \text { Total effect } \\ \beta(\mathrm{SE}) & \beta(\mathrm{SE}) & \beta \text { (SE) }\end{array}$

\begin{tabular}{lccc}
\hline Psychological control $\left(R^{2}=0.13\right)$ & & - & $0.04^{*}(0.016)$ \\
Openness & - & - & $-0.15^{* *}(0.016)$ \\
Conscientiousness & - & - & $0.03(0.016)$ \\
Extraversion & - & - & $0.10^{* *}(0.015)$ \\
Agreeableness & - & - & $0.15^{* *}(0.015)$ \\
Neuroticism & - & - & $-0.12^{* *}(0.014)$ \\
Age & - & - & $-0.03^{*}(0.014)$ \\
Sex & - & - & $-0.07^{* *}(0.016)$ \\
Parental SES & - & - & $-0.13^{* *}(0.017)$ \\
Parental well-being & - & - & $0.37^{* *}(0.032)$ \\
Covariance & & - & $0.17^{* *}(0.016)$ \\
SDQint \& SDQext & - & - & $-0.25^{* *}(0.017)$ \\
Warmth \& behavioural control & - & - & $0.26^{* *}(0.014)$ \\
Warmth \& psychological control & - & - & \\
Behavioural \& psychological control & - & - \\
\hline
\end{tabular}

Notes. Sex is coded with male as the reference category (female $=50.9 \% \mathrm{CI}=49.4-52.3$ ) and parental socioeconomic status (SES) with low as the reference category. $\beta=$ Standardized beta coefficient; $S E$ Standard error. $\chi^{2}=3151.75, p<0.001, C F I=1.00, T L I=1.00, R M S E A<0.01$, $R^{2}=0.39$

$* p<0.05$

$* * p<0.01$

Fig. 2 Standardized coefficients from SEM showing indirect effects of parental personality (OCEAN) and parenting dimensions (warmth, behavioural control, and psychological control) on adolescent internalizing (SDQint; long-dashed lines) and externalizing problems (SDQext; short-dashed lines). Only significant paths are shown and marked by $* * p<0.01$ and $* p<0.05$. Age, sex, parental SES, and parental well-being are not shown in the figure but were included as covariates in the analyses. Model fit indices: $\chi^{2}=$ $3151.75, p<0.001, C F I=1.00$, $T L I=1.00, R M S E A<0.01$, $R^{2}=0.39$

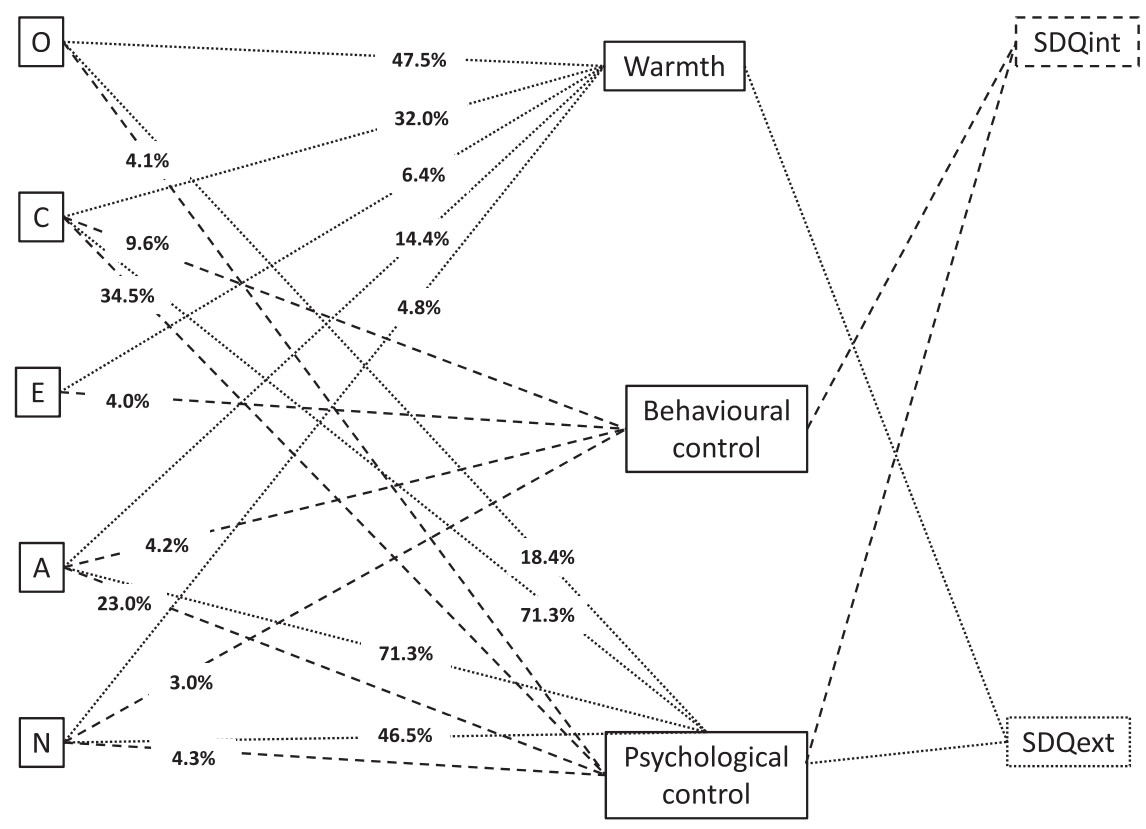

explained by a frequent and disproportionally high negative reactivity towards stressful events (i.e., stress reactivity theory, Bolger \& Schilling, 1991, Mazza et al., 2020, Ortiz Ruiz, 2018). More frequent negative life events, maladaptive emotional coping strategies, and overreactivity in response to stress have been identified as mechanisms by which neurotic parents supposedly create a stressful and insecure environment lacking support and stress regulation competency and therefore linked to children's mental health problems (Ellenbogen \& Hodgins, 2004). In this light, the 
present finding that adolescent internalizing problems are more affected by parental neuroticism than externalizing problems seems plausible. In conclusion, future studies should include stress reactivity and regulation competency to yield further explanatory evidence.

Moreover, as expected, the results indicated that adolescents with parents high in conscientiousness had fewer externalizing problems, while a parental personality high in extraversion showed adolescents with fewer internalizing problems but not vice versa. Low conscientiousness has been discussed as indicative of poor mental health, owing to a vulnerability towards negative self-perceptions, low selfefficacy, and poor coping abilities (Kotov et al., 2010). Hence, strengthening competencies that enable parents to deal with challenging life events and to develop a positive self-image are not only key factors for their own mental health and health behaviour in daily life but may also help to promote the mental health of their children (Bolger \& Schilling, 1991, Wrosch \& Scheier, 2003).

High parental extraversion may be particularly beneficial for adolescent emotional well-being and social relations with peers, as suggested by lower internalizing problems (e.g., Ortiz Ruiz, 2018). This mechanism is still not fully explored, but it has been hypothesized that extraverts may react more positively to social situations that contribute to greater mental health, even after controlling for the amount of social contact (Diener et al., 1992, Lucas et al., 2008). More research is needed to clarify how strong parental extraversion correlates with the extraversion levels of their children and whether this correlation explains the findings on adolescent social and emotional well-being that may be mediated via behavioural factors.

Parental openness to new experience and agreeableness were directly associated with rather adverse parenting (low parental warmth and high psychological control) but not with child mental health problems. However, results showed several indirect associations with adolescent internalizing and externalizing problems. Interpreting these findings is difficult due to the few and mixed findings, so far. Whereas some studies found positive associations between parental openness or agreeableness and their children's externalizing problems others found the opposite pattern (Nigg \& Hinshaw, 1998, Oliver et al., 2009, Prinzie et al., 2004). Possible explanatory approaches are close relationships between openness and sensation seeking (Nigg \& Hinshaw, 1998) or agreeableness and inconsistent parenting (i.e., laxness followed by overreaction; Prinzie et al., 2004) but require further scientific attention.

\section{Parenting and Adolescent Mental Health Problems}

As predicted, parenting characterized by warmth was related to fewer adolescent externalizing problems. Additionally, high levels of parental behavioural control were related to fewer adolescent internalizing problems but not externalizing problems. In contrast, parental psychological control was related to a higher risk of externalizing and internalizing problems in adolescents.

Thus, the present findings substantiate previous indications of a positive association between parental warmth and adolescent psychological adjustment and coping, as well as parents' behavioural control and their children's selfregulation and compliance, which lead to better mental health (Aunola \& Nurmi, 2005, Barber et al., 1994, Buschgens et al., 2010, Solomon, 2000, Yap \& Jorm, 2015). The combination of both parenting dimensions (i.e., warmth and behavioural control) has been proposed as particularly supportive of adolescent mental health by different studies (this combination has been termed "authoritative parenting”; Calders et al., 2020, Steinberg, 2001). Moreover, the results highlight the magnitude of parental psychological control on different aspects of adolescent mental health (Buschgens et al., 2010). Parental psychological control is characterized by non-responsiveness to a child's psychological needs and discouragement of autonomous thinking or acting. It has adverse effects on adolescents' mental health, as it disrupts the development of autonomy and behaviour becomes shaped by external demands rather than being self-determined (Barber et al., 1994, Steinberg \& Silk, 2002).

Although the direction of causality is not yet clear, the present findings support prior theoretical assumptions (Belsky, 1997) and empirical evidence (e.g., Bayer et al., 2019, Gölcük \& Berument, 2019, Hutchings \& Lane, 2005) regarding the relationship between parenting and child mental health. This is particularly important with respect to the fact that parenting behaviours, in contrast to other risk factors, can be addressed by public health measures (Achtergarde et al., 2015).

\section{The Mediating Role of Parenting}

The present results suggest that parenting dimensions explain a significant proportion of the variance in associations between parents' personality and their children's mental health problems. In line with previous findings, the analyses showed indirect effects via parental behavioural control on adolescent mental health problems, but they were limited to internalizing problems (Bayer et al., 2019, Oliver et al., 2009, Prinzie et al., 2004). One possible explanation includes the different operationalization of parental behavioural control; one can differentiate between "proactive control" (e.g., parents establish rules and limitations to facilitate desired child behaviour) and "reactive control" (e.g., punishment in reaction to undesired child behaviour; Calders et al., 2020). The latter is supposed to negatively 
affect adolescent externalizing problems (Calders et al., 2020). In the present study, the operationalization of parental behavioural control represents proactive control rather than reactive control, and its absence may have influenced children's internalizing problems but not externalizing problems. More research is needed to disentangle different facets of parental control and their associations with different mental health outcomes.

Furthermore, the present findings support and extend previous research on the positive effect of parental conscientiousness and extraversion on adolescents' mental health, which can be explained by parental warmth as well as behavioural control (Lucas et al., 2008, Oliver et al., 2009). The results replicated negative associations between parental neuroticism as well as psychological control and adolescent mental health and highlighted their mutually reinforcing negative effect (Prinzie et al., 2004, Yap \& Jorm, 2015). Overall, combinations of parental conscientiousness and neuroticism with parental warmth and psychological control explained noticeable variance (>30\%) in adolescent mental health compared to the other mediation effects. For instance, we found an indirect effect between parental agreeableness and adolescent mental health problems mediated via high parental psychological control as well as low parental warmth (explained variance was less than $15 \%$ ).

In conclusion, based on the present findings, high parental agreeableness may manifest in adverse parenting behaviour and therefore seems to be a reasonable factor for developing intervention measures with a focus on parenting. However, findings regarding the role of agreeableness are still inconclusive, although results from a longitudinal study highlight parental agreeableness and extraversion for child mental health as relevant parental characteristics (de Haan et al., 2012). Hence, specific combinations of parental personality and parenting dimensions need further investigation.

\section{Limitations}

Some study limitations should be considered when interpreting these findings. First, cross-sectional data were used, which eliminated the possibility of drawing conclusions about developmental changes during adolescence, for instance, changes in levels of perceived autonomy or parental adjustment of behavioural control. Consequently, the findings cannot be used to explain causal pathways. Second, mother and father reports were not equally balanced in the present data $(82.5 \%$ were mothers) due to the KiGGS sampling procedure aimed at only one parent of the recruited adolescent. Future studies should differentiate between mothers' and fathers' parenting behaviour to investigate the separate effects of psychological control (e.g., Deb \& McGirr, 2015). Additionally, different personality constellations between parents and mother-father interactions may also play a role in adolescent mental health and should be considered in future work. Another limitation refers to the use of the short 10-item BFI personality inventory, which reflects only a broad indication of the five distinct personality dimensions. Finally, the study results are based on a large sample of the German population but cannot be generalized to other cultural contexts (external validity) and show a lack of real-time reports or behavioural approaches (ecological validity).

\section{Practical Implications}

The present results support the association between parental personality and parenting behaviour related to adolescent mental health and thereby offer entry points for public mental health interventions. More precisely, the results can add value to existing prevention and early intervention programmes targeting parents by considering the role of parental personality in parenting behaviour and its effect on their children's mental health. The current research found indications for high parental conscientiousness and extraversion as potentially supportive factors for adolescent mental health in combination with high parental warmth and behavioural control as well as low psychological control. In contrast, high parental neuroticism and psychological control increase the risk of adolescent mental health problems. In addition, parenting characterized by behavioural control seems more relevant for the prevention of adolescent internalizing problems, whereas parental warmth may support the prevention of externalizing problems.

Interventions focusing on parenting skills outside the clinical setting (e.g., how to use clear and calm instructions, logical consequences for misbehaviour) have gained more attention and often target parents or parents with their children (Medlow et al., 2016, Tarver et al., 2014). For instance, the Positive Parenting Programme (Triple P; Sanders et al., 2014, Sanders et al., 2000) aims to prevent and offer treatment for children's behavioural and emotional problems. Moreover, the Strengthening Families Programme (SFP; Kumpfer \& Magalhães, 2018, Kumpfer et al., 1996) focuses on prevention and intervention with children at risk of substance abuse and delinquency. On the other hand, community-based parent interventions working with parents' personality are not yet well investigated and far from implemented, although the first suggestions on how to integrate parental personality into parental education programmes have already been published (Achtergarde et al., 2015). Hereby, Achtergarde et al. (2015) formulated basic questions focusing on child temperament ("What do children need from their parents according to their temperament?"), parental personality ("What do parents need to improve their parenting according to their personality?"), interfering fit ("What to do when parent and child do not fit 
together in terms of temperament and personality?"), and possible answers (e.g., in cases of high extraversion, parents may profit from "social feedback" and "group training") to help guide individually tailored parental interventions. Universal or indicated prevention programmes targeting parenting skills in consideration of personality traits may be effective in reducing adolescent mental health problems to some extent. For instance, raising awareness and knowledge about maladaptive mechanisms may be a good entry point.

Current directions within personality psychology research suggest that personality traits show both continuity and change related to life transitions and important events over the life course (Wrzus \& Roberts, 2017). In addition, several clinical studies show how personality changes in response to interventions, especially neuroticism, are subject to variation, followed by extraversion (see metaanalysis by Roberts et al., 2017). Additionally, personality interventions can have surprisingly rapid effects; both shortand long-term personality changes have been reported after only eight weeks of intervention (Roberts et al., 2017).

In conclusion, the present findings suggest that prevention measures addressing the general population may not be as efficient as indicated prevention (see recent meta-analysis by Leijten et al., 2019). Thus, further efforts are needed to include parental personality in existing programmes and to identify other unconsidered factors for universal prevention approaches that help parents recognize problematic personality mechanisms at an early stage, change maladaptive parenting behaviour, and thereby contribute to the healthy development of their children.

Acknowledgements We are particularly grateful to all study participants and acknowledge the assistance given by the collaborators in providing vigorous support and premises in the 167 study locations. Our grateful thanks are also extended to our colleagues from the Robert Koch Institute for their high engagement and valuable contribution to this project. Krisitn Göbel is now working as a research associate at the Freie Universität Berlin, Department of Education and Psychology, Developmental Science and Applied Developmental Psychology Division.

Funding The present research was supported by the German Ministry of Health (BMG) [grant number ZMV1-2516-FSB-703].

Funding Open Access funding enabled and organized by Projekt DEAL.

\section{Compliance with Ethical Standards}

Conflict of Interest The authors declare no competing interests.

Publisher's note Springer Nature remains neutral with regard to jurisdictional claims in published maps and institutional affiliations.

Open Access This article is licensed under a Creative Commons Attribution 4.0 International License, which permits use, sharing, adaptation, distribution and reproduction in any medium or format, as long as you give appropriate credit to the original author(s) and the source, provide a link to the Creative Commons license, and indicate if changes were made. The images or other third party material in this article are included in the article's Creative Commons license, unless indicated otherwise in a credit line to the material. If material is not included in the article's Creative Commons license and your intended use is not permitted by statutory regulation or exceeds the permitted use, you will need to obtain permission directly from the copyright holder. To view a copy of this license, visit http://creativecommons. org/licenses/by/4.0/.

\section{References}

Achtergarde, S., Postert, C., Wessing, I., Romer, G., \& Müller, J. M. (2015). Parenting and child mental health: Influences of parent personality, child temperament, and their interaction. The Family Journal, 23(2), 167-179.

Amrock, S. M., \& Weitzman, M. (2014). Parental psychological distress and children's mental health: Results of a national survey. Academic Pediatrics, 14(4), 375-381.

Anaya, B., \& Perez-Edgar, K. (2019). Personality development in the context of individual traits and parenting dynamics. New Ideas Psychol, 53, 37-46. https://doi.org/10.1016/j.newideapsych. 2018.03.002.

Aunola, K., \& Nurmi, J. E. (2005). The role of parenting styles in children's problem behavior. Child Development, 76(6), 1144-1159. https://doi.org/10.1111/j.1467-8624.2005.00840.x-i1.

Bahrami, B., Dolatshahi, B., Pourshahbaz, A., \& Mohammadkhani, P. (2018). Comparison of personality among mothers with different parenting styles. Iran J Psychiatry, 13(3), 200-206.

Barber, B. K., Olsen, J. E., \& Shagle, S. C. (1994). Associations between parental psychological and behavioral control and youth internalized and externalized behaviors. Child Development, 65(4), 1120-1136. https://doi.org/10.1111/j.1467-8624.1994.tb00807.x.

Baumgarten, F., Klipker, K., Göbel, K., Janitza, S., \& Hölling, H. (2018). The developmental course of mental health problems among children and adolescents. Results of the KiGGS cohort. Journal of Health Monitoring, 3(1), 57-61. https://doi.org/10. 17886/rki-gbe-2018-028.

Baumrind, D. (1971). Current patterns of parental authority. Developmental Psychology Monograph, 4(1), 1-103. Pt. 2.

Bayer, J. K., Morgan, A., Prendergast, L. A., Beatson, R., Gilbertson, T., Bretherton, L., \& Rapee, R. M. (2019). Predicting temperamentally inhibited young children's clinical-level anxiety and internalizing problems from parenting and parent wellbeing: a population study. J Abnorm Child Psychol, 47(7), 1165-1181. https://doi.org/10.1007/s10802-018-0442-6.

Bayer, J. K., Rapee, R. M., Hiscock, H., Ukoumunne, O. C., Mihalopoulos, C., \& Wake, M. (2011). Translational research to prevent internalizing problems early in childhood. Depress Anxiety, 28(1), 50-57. https://doi.org/10.1002/da.20743.

Belsky, J. (1984). The determinants of parenting: A process mode. Child Development, 55, 83-96.

Belsky, J. (1997). Attachment, mating, and parenting. Human Nature, 8(4), 361-381. https://doi.org/10.1007/bf02913039.

Belsky, J., \& Barends, N. (2002). Personality and parenting. In Handbook of parenting: Being and becoming a parent (Vol. 3, 2nd ed., pp. 415-438). Lawrence Erlbaum Associates Publishers.

Bertino, M. D., Connell, G., \& Lewis, A. J. (2012). The association between parental personality patterns and internalising and externalising behaviour problems in children and adolescents. Clinical Psychologist, 16(3), 110-117. https://doi.org/10.1111/j. 1742-9552.2012.00042.x. 
Bolger, N., \& Schilling, E. A. (1991). Personality and the problems of everyday life: The role of neuroticism in exposure and reactivity to daily stressors. Journal of Personality, 59(3), 355-386. https:// doi.org/10.1111/j.1467-6494.1991.tb00253.x.

Bornstein, M. H., Hahn, C.-S., \& Haynes, O. M. (2011). Maternal personality, parenting cognitions, and parenting practices. Developmental Psychology, 47(3), 658-675. https://doi.org/10. 1037/a0023181.

Brauns, H., Scherer, S., \& Steinmann, S. (2003). The CASMIN Educational Classification in International Comparative Research. In J. H. P. Hoffmeyer-Zlotnik \& C. Wolf (Eds.), Advances in cross-national comparison: A European working book for demographic and socio-economic variables (pp. 221-244). Springer US. https://doi.org/10.1007/978-1-4419-9186-7_11.

Brook, J. S., Whiteman, M., \& Zheng, L. (2002). Intergenerational transmission of risks for problem behavior. Journal of Abnormal Child Psychology, 30(1), 65-76. https://doi.org/10.1023/a: 1014283116104.

Buschgens, C. J., van Aken, M. A., Swinkels, S. H., Ormel, J., Verhulst, F. C., \& Buitelaar, J. K. (2010). Externalizing behaviors in preadolescents: familial risk to externalizing behaviors and perceived parenting styles. Eur Child Adolesc Psychiatry, 19(7), 567-575. https://doi.org/10.1007/s00787-009-0086-8.

Calders, F., Bijttebier, P., Bosmans, G., Ceulemans, E., Colpin, H., Goossens, L., \& Leeuwen, K. V. (2020). Investigating the interplay between parenting dimensions and styles, and the association with adolescent outcomes. European Child \& Adolescent Psychiatry, 29(3), 327-342.

Cummins, R. A., Eckersley, R., Pallant, J., van Vugt, J., \& Misajon, R. (2003). Developing a national index of subjective wellbeing: The Australian unity wellbeing index. Social Indicators Research, 64 (2), 159-190. https://doi.org/10.1023/a:1024704320683.

de Haan, A. D., Dekovic, M., \& Prinzie, P. (2012). Longitudinal impact of parental and adolescent personality on parenting. Journal of Personality and Social Psychology, 102(1), 189-199. https://doi.org/10.1037/a0025254.

Deb, S., \& McGirr, K. (2015). Role of home environment, parental care, parents personality and their relationship to adolescent mental health. Journal of Psychology \& Psychotherapy, 05(06). https://doi.org/10.4172/2161-0487.1000223.

Diener, E., Sandvik, E. D., Pavot, W., \& Fujita, F. (1992). Extraversion and subjective well-being in a US national probability sample. Journal of Research in Personality, 26(3), 205-215. https://doi.org/10.1016/0092-6566(92)90039-7.

Ellenbogen, M. A., \& Hodgins, S. (2004). The impact of high neuroticism in parents on children's psychosocial functioning in a population at high risk for major affective disorder: A family-environmental pathway of intergenerational risk. Development and Psychopathology, 16, 113-136.

Evans, G. W., Li, D., \& Whipple, S. S. (2013). Cumulative risk and child development. Psychological Bulletin, 139(6), 1342.

Fraley, R. C., \& Shaver, P. R. (2008). Attachment theory and its place in contemporary personality theory and research. In O. John \& R. W. Robins (Eds.), Handbook of personality: Theory and research (3rd Edition) (pp. 518-541). Guilford Press.

Ganzeboom, H. B. G., \& Treiman, D. J. (2003). Three internationally standardised measures for comparative research on occupational status. In J. H. P. Hoffmeyer-Zlotnik \& C. Wolf (Eds.), Advances in cross-national comparison: A European working book for demographic and socio-economic variables (pp. 159-193). Springer US. https://doi.org/10.1007/978-1-4419-9186-7_9.

Garcia, O. F., Fuentes, M. C., Gracia, E., Serra, E., \& Garcia, F. (2020). Parenting warmth and strictness across three generations: Parenting styles and psychosocial adjustment. International Journal of Environmental Research and Public Health, 17(20). https://doi.org/10.3390/ijerph17207487.
Göbel, K., \& Cohrdes, C. (2021). The whole is greater than the sum of its parts: profiles of multiple mental health risk factors using Latent class analysis. Child and Adolescent Psychiatry and Mental Health, 15(1), 1-15.

Gölcük, M., \& Berument, S. K. (2019). The relationship between negative parenting and child and maternal temperament. Current Psychology, 40(7), 3596-3608. https://doi.org/10.1007/s12144019-00307-9.

Goodman, A., Lamping, D. L., \& Ploubidis, G. B. (2010). When to use broader internalising and externalising subscales instead of the hypothesised five subscales on the Strengths and Difficulties Questionnaire (SDQ): data from British parents, teachers and children. Journal of Abnormal Child Psychology, 38(8), 1179-1191. https://doi.org/10.1007/s10802-010-9434-x.

Goodman, R. (1997). The Strengths and Difficulties Questionnaire: A research note. Journal of Child Psychology and Psychiatry, 38(5), 581-586. https://doi.org/10.1111/j.1469-7610.1997.tb01545.x.

Hair, E. C., Moore, K. A., Garrett, S. B., Ling, T., \& Cleveland, K. (2008). The continued importance of quality parent-adolescent relationships during late adolescence. Journal of Research on Adolescence, 18(1), 187-200. https://doi.org/10.1111/j.15327795.2008.00556.x.

Hong, R. Y., Tan, C. S., Lee, S. S., Tan, S.-H., Tsai, F.-F., Poh, X.-T., \& Zhou, Y. (2015). Interactive effects of parental personality and child temperament with parenting and family cohesion. Parenting, 15(2), 92-118.

Hu, L. T., \& Bentler, P. M. (1999). Cutoff criteria for fit indexes in covariance structure analysis: Conventional criteria versus new alternatives. Structural Equation Modeling: A Multidisciplinary Journal, 6(1), 1-55. https://doi.org/10.1080/10705519909540118.

Hutchings, J., \& Lane, E. (2005). Parenting and the development and prevention of child mental health problems. Current Opinion in Psychiatry, 18(4), 386-391. https://doi.org/10.1097/01.yco. 0000172056.63401.e0.

Huver, R. M., Otten, R., de Vries, H., \& Engels, R. C. (2010). Personality and parenting style in parents of adolescents. Journal of Adolescence, 33(3), 395-402. https://doi.org/10.1016/j. adolescence.2009.07.012.

John, O. P., Naumann, L. P., \& Soto, C. J. (2008). Paradigm shift to the integrative Big Five trait taxonomy: History, measurement, and conceptual issues. In O. P. John, R. W. Robins, \& L. A. Pervin (Eds.), Handbook of personality: Theory and research (pp. 114-158). The Guilford Press.

Kieling, C., Baker-Henningham, H., Belfer, M., Conti, G., Ertem, I., Omigbodun, O., \& Rahman, A. (2011). Child and adolescent mental health worldwide: evidence for action. The Lancet, 378(9801), 1515-1525. https://doi.org/10.1016/s0140-6736(11)60827-1.

Klasen, H., Woerner, W., Wolke, D., Meyer, R., Overmeyer, S., Kaschnitz, W., \& Goodman, R. (2000). Comparing the German versions of the Strengths and Difficulties Questionnaire (SDQDeu) and the Child Behavior Checklist. European Child \& Adolescent Psychiatry, 9(4), 271-276. https://doi.org/10.1007/ s007870070030.

Kenny, D. A. (2020). Measuring model fit. Retrieved from: http://www.davidakenny.net/cm/fit.html.

Kline, R. B. (2015). Principles and practice of structural equation modeling ( $4^{\text {th }} \mathrm{Ed}$.). New York, London: Guilford publications.

Klipker, K., Baumgarten, F., Göbel, K., Lampert, T., \& Hölling, H. (2018). Mental health problems in children and adolescents in Germany. Results of the cross-sectional KiGGS Wave 2 study and trends. Journal of Health Monitoring, 3(3), 37-45. https:// doi.org/10.17886/rki-gbe-2018-084.

Kotov, R., Gamez, W., Schmidt, F., \& Watson, D. (2010). Linking "big" personality traits to anxiety, depressive, and substance use disorders: a meta-analysis. Psychological Bulletin, 136(5), 768-821. https://doi.org/10.1037/a0020327. 
Kumpfer, K. L., \& Magalhães, C. (2018). Strengthening Families Program: An evidence-based family intervention for parents of high-risk children and adolescents. Journal of Child \& Adolescent Substance Abuse, 27(3), 174-179. https://doi.org/10.1080/ 1067828x.2018.1443048.

Kumpfer, K. L., Molgaard, V., \& Spoth, R. (1996). The Strengthening Families Program for the prevention of delinquency and drug use. In R. D. Peters \& R. J. McMahon (Eds.), Preventing childhood disorders, substance abuse, and delinquency (pp. 241-267). Sage Publications, Inc. https://doi.org/10.4135/9781483327679.n11.

Lampert, T., Müters, S., Stolzenberg, H., \& Kroll, L. E., KiGGS Study Group. (2014). Measurement of socioeconomic status in the KiGGS study: First follow-up (KiGGS Wave 1). Bundesgesundheitsblatt, Gesundheitsforschung, Gesundheitsschutz, 57(7), 762-770. https://doi.org/10.1007/s00103-014-1974-8.

Lange, M., Hoffmann, R., Mauz, E., Houben, R., Gößwald, A., Rosario, A. S., \& Kurth, B.-M. (2018). KiGGS Wave 2 longitudinal component - data collection design and developments in the numbers of participants in the KiGGS cohort. Journal of Health Monitoring, 3, 92-107. https://doi.org/10.17886/RKIGBE-2018-035.

Leijten, P., Gardner, F., Melendez-Torres, G. J., van Aar, J., Hutchings, J., Schulz, S., \& Overbeek, G. (2019). Meta-analyses: Key parenting program components for disruptive child behavior. Journal of American Academy of Child \& Adolescent Psychiatry, 58(2), 180-190. https://doi.org/10.1016/j.jaac.2018.07.900.

Lucas, R. E., Le, K., \& Dyrenforth, P. S. (2008). Explaining the extraversion/positive affect relation: sociability cannot account for extraverts' greater happiness. Journal of Personality, 76(3), 385-414. https://doi.org/10.1111/j.1467-6494.2008.00490.x.

Mabbe, E., Vansteenkiste, M., Brenning, K., De Pauw, S., Beyers, W., \& Soenens, B. (2019). The moderating role of adolescent personality in associations between psychologically controlling parenting and problem behaviors: A longitudinal examination at the level of within-person change. Developmental Psychology, 55 (12), 2665-2677. https://doi.org/10.1037/dev0000802.

MacKinnon, D. P., Lockwood, C. M., \& Williams, J. (2004). Confidence limits for the indirect effect: Distribution of the product and resampling methods. Multivariate Behavioral Research, 39 (1), 99. https://doi.org/10.1207/s15327906mbr3901_4.

Mastrotheodoros, S., Van der Graaff, J., Deković, M., Meeus, W. H. J., \& Branje, S. J. T. (2018). Coming closer in adolescence: Convergence in mother, father, and adolescent reports of parenting. Journal of Research on Adolescence, Advanced online publication, 1-17. https://doi.org/10.1111/jora.12417.

Mauz, E., Gößwald, A., Kamtsiuris, P., Hoffmann, R., Lange, M., Schenck, U. V., \& Kurth, B.-M. (2017). New data for action. Data collection for KiGGS Wave 2 has been completed. Journal of Health Monitoring, 2(S3), 2-27. https://doi.org/10.17886/rkigbe-2017-105.

Mazza, C., Ricci, E., Marchetti, D., Fontanesi, L., Di Giandomenico, S., Verrocchio, M. C., \& Roma, P. (2020). How personality relates to distress in parents during the Covid-19 lockdown: The mediating role of child's emotional and behavioral difficulties and the moderating effect of living with other people. Internationl Journal of Environmental Research and Public Health, 17(17). https://doi.org/10.3390/ijerph17176236.

McCrae, R. R., \& Costa Jr, P. T. (2003). Personality in adulthood: A five-factor theory perspective, 2nd ed. Guilford Press. https://doi. org/10.4324/9780203428412.

Medlow, S., Klineberg, E., Jarrett, C., \& Steinbeck, K. (2016). A systematic review of community-based parenting interventions for adolescents with challenging behaviours. Journal of Adolescence, 52, 60-71. https://doi.org/10.1016/j.adolescence.2016.07.003.

Milevsky, A., Schlechter, M., Netter, S., \& Keehn, D. (2006). Maternal and paternal parenting styles in adolescents: Associations with self- esteem, depression and life-satisfaction. Journal of Child and Family Studies, 16(1), 39-47. https://doi.org/10.1007/s10826-0069066-5.

Moilanen, K. L., Rasmussen, K. E., \& Padilla-Walker, L. M. (2015). Bidirectional associations between self-regulation and parenting styles in early adolescence. Journal of Research on Adolescence, 25(2), 246-262. https://doi.org/10.1111/jora.12125.

Muthén, L., \& Muthén, B. (2011). Mplus User's Guide 5th ed. Los Angeles: CA; 1998-2007. Muthén \& Muthén.

Nigg, J. T., \& Hinshaw, S. P. (1998). Parent personality traits and psychopathology associated with antisocial behaviors in childhood attention-deficit hyperactivity disorder. The Journal of Child Psychology and Psychiatry and Allied Disciplines, 39(2), 145-159. https://doi.org/10.1017/S0021963097001984.

Noftle, E. E., \& Shaver, P. R. (2006). Attachment dimensions and the big five personality traits: Associations and comparative ability to predict relationship quality. Journal of Research in Personality, 40(2), 179-208. https://doi.org/10.1016/j.jrp.2004.11.003.

Oliver, P. H., Guerin, D. W., \& Coffman, J. K. (2009). Big five parental personality traits, parenting behaviors, and adolescent behavior problems: A mediation model. Personality and Individual Differences, 47(6), 631-636. https://doi.org/10.1016/j.paid. 2009.05.026.

Ortiz Ruiz, R. M. A. B., \& Jacqueline (2018). Temperament, parental personality and parenting stress in relation to socio-emotional development at 51 months. Early Child Development and Care, 189(12), 1978-1991. https://doi.org/10.1080/03004430.2018. 1425297.

Patel, V., Flisher, A. J., Hetrick, S., \& McGorry, P. (2007). Mental health of young people: a global public-health challenge. The Lancet, 369(9569), 1302-1313. https://doi.org/10.1016/s01406736(07)60368-7.

Paus, T., Keshavan, M., \& Giedd, J. N. (2008). Why do many psychiatric disorders emerge during adolescence? [Perspective]. Nature Reviews Neuroscience, 9, 947. https://doi.org/10.1038/nrn2513.

Petito, F., \& Cummins, R. A. (2012). Quality of life in adolescence: The role of perceived control, parenting style, and social support. Behaviour Change, 17(3), 196-207. https://doi.org/10.1375/bech. 17.3.196.

Pettit, G. S., Laird, R. D., Dodge, K. A., Bates, J. E., \& Criss, M. M. (2001). Antecedents and behavior-problem outcomes of parental monitoring and psychological control in early adolescence. Child Development, 72(2), 583-598. https://doi.org/10.1111/14678624.00298.

Picoito, J., Santos, C., \& Nunes, C. (2021). Heterogeneity and heterotypic continuity of emotional and behavioural profiles across development. Social Psychiatry and Psychiatric Epidemiology, 56(5), 807-819. https://doi.org/10.1007/s00127-020-01903-y.

Pinquart, M. (2017). Associations of parenting dimensions and styles with externalizing problems of children and adolescents: An updated meta-analysis. Developmental Psychology, 53(5), 873-932. https://doi.org/10.1037/dev0000295.

Polanczyk, G. V., Salum, G. A., Sugaya, L. S., Caye, A., \& Rohde, L. A. (2015). Annual research review: A meta-analysis of the worldwide prevalence of mental disorders in children and adolescents. Journal of Child Psychology and Psychiatry, 56(3), 345-365. https://doi.org/10.1111/jcpp.12381.

Preacher, K. J., \& Kelley, K. (2011). Effect size measures for mediation models: quantitative strategies for communicating indirect effects. Psychological Methods, 16(2), 93-115. https://doi.org/10. 1037/a0022658.

Prinzie, P., Onghena, P., Hellinckx, W., Grietens, H., Ghesquière, P., \& Colpin, H. (2004). Parent and child personality characteristics as predictors of negative discipline and externalizing problem behaviour in children. European Journal of Personality, 18(2), 73-102. https://doi.org/10.1002/per.501. 
Prinzie, P., Stams, G. J., Dekovic, M., Reijntjes, A. H., \& Belsky, J. (2009). The relations between parents' Big Five personality factors and parenting: a meta-analytic review. Journal of Personality and Social Psychology, 97(2), 351-362. https://doi.org/10.1037/a 0015823.

Puff, J., \& Renk, K. (2016). Mothers' temperament and personality: Their relationship to parenting behaviors, locus of control, and young children's functioning. Child Psychiatry and Human Development, 47(5), 799-818. https://doi.org/10.1007/s10578015-0613-4.

Raboteg-Saric, Z., \& Sakic, M. (2013). Relations of parenting styles and friendship quality to self-esteem, life satisfaction and happiness in adolescents. Applied Research in Quality of Life, 9(3), 749-765. https://doi.org/10.1007/s11482-013-9268-0.

Rammstedt, B., \& John, O. P. (2007). Measuring personality in one minute or less: A 10-item short version of the Big Five Inventory in English and German. Journal of Research in Personality, 41 (1), 203-212. https://doi.org/10.1016/j.jrp.2006.02.001.

Reitzle, M., Winkler Metzke, C., \& Steinhausen, H.-C. (2001). Eltern und Kinder: Der Zürcher Kurzfragebogen zum Erziehungsverhalten (ZKE). [Parents and children: The Zurich Brief Questionnaire for the Assessment of Parental Behavior.]. Diagnostica, 47(4), 196-207. https://doi.org/10.1026//0012-1924.47.4.196.

Roberts, B. W., Luo, J., Briley, D. A., Chow, P. I., Su, R., \& Hill, P. L. (2017). A systematic review of personality trait change through intervention. Psychological Bulletin, 143(2), 117-141. https://doi. org/10.1037/bul0000088.

Sahithya, B. R., \& Raman, V. (2021). Influence of parental personality on parenting styles: A scoping review of literature. International Journal of Psychology Sciences, 3(1), 4-11.

Sanders, M. R., Kirby, J. N., Tellegen, C. L., \& Day, J. J. (2014). The Triple P-Positive Parenting Program: a systematic review and meta-analysis of a multi-level system of parenting support. Clinical Psychology Review, 34(4), 337-357. https://doi.org/10. 1016/j.cpr.2014.04.003.

Sanders, M. R., Markie-Dadds, C., Tully, L. A., \& Bor, W. (2000). The Triple P-Positive Parenting Program: A Comparison of enhanced, standard, and self-directed behavioral family intervention for parents of children with early onset conduct problems. Journal of Consulting and Clinical Psychology, 68(4), 624-640.

Scaramella, L. V., Conger, R. D., \& Simons, R. L. (1999). Parental protective influences and gender-specific increases in adolescent internalizing and externalizing problems. Journal of Research on Adolescence, 9(2), 111-141. https://doi.org/10.1207/s15327795jra 0902_1.
Solomon, M. (2000). The fruits of their labors: A longitudinal exploration of parent personality and adjustment in their adult children. Journal of Personality, 68(2), 281-308. https://doi.org/ 10.1111/1467-6494.00098.

Steinberg, L. (2001). We know some things: Parent-adolescent relationships in retrospect and prospect. Journal of Research on Adolescence, 11(1), 1-19. https://doi.org/10.1111/1532-7795.00001.

Steinberg, L., \& Silk, J. S. (2002). Parenting adolescents. In Handbook of parenting: Children and parenting, Vol. 1, 2nd ed. (pp. 103-133). Lawrence Erlbaum Associates Publishers.

Tarver, J., Daley, D., Lockwood, J., \& Sayal, K. (2014). Are selfdirected parenting interventions sufficient for externalising behaviour problems in childhood? A systematic review and metaanalysis. Eur Child Adolesc Psychiatry, 23(12), 1123-1137. https://doi.org/10.1007/s00787-014-0556-5.

Vafaeenejad, Z., Elyasi, F., Moosazadeh, M., \& Shahhosseini, Z. (2018). Psychological factors contributing to parenting styles: A systematic review. F1000Research, 7. https://doi.org/10.12688/ f1000research.14978.1.

Vafaeenejad, Z., Elyasi, F., Moosazadeh, M., \& Shahhosseini, Z. (2020). Investigating the predictive role of personality traits on parenting styles in couples of 6-12 years children. European Journal of Environment and Public Health, 4(2), em0041. https:// doi.org/10.29333/ejeph/8215.

Wang, F. L., Feldman, J. S., Lemery-Chalfant, K., Wilson, M. N., \& Shaw, D. S. (2019). Family-based prevention of adolescents' cooccurring internalizing/externalizing problems through early childhood parent factors. Journal of Consulting and Clinical Psychology, 87(11), 1056-1067. https://doi.org/10.1037/ccp0000439.

Woerner, W., Becker, A., \& Rothenberger, A. (2004). Normative data and scale properties of the German parent SDQ. European Child \& Adolescent Psychiatry, 13(2), ii3-ii10. https://doi.org/10.1007/ s00787-004-2002-6.

Wrosch, C., \& Scheier, M. F. (2003). Personality and quality of life: the importance of optimism and goal adjustment. Quality of Life Research, 12(Suppl 1), 59-72. https://doi.org/10.1023/A: 1023529606137.

Wrzus, C., \& Roberts, B. W. (2017). Processes of personality development in adulthood: The TESSERA Framework. Personality and Social Psychology Review, 21(3), 253-277. https://doi.org/ $10.1177 / 1088868316652279$.

Yap, M. B. H., \& Jorm, A. F. (2015). Parental factors associated with childhood anxiety, depression, and internalizing problems: A systematic review and meta-analysis. Journal of Affective Disorders, 175, 424-440. https://doi.org/10.1016/j.jad.2015.01.050. 